\title{
A report on freshwater tailless flea, Simocephalus vetulus from Haridwar, located in foothills of Shivalik Himalaya in Uttarakhand, India
}

\author{
Anand Mishra* \\ Department of Zoology and Environmental Science, Gurukula Kangri University Haridwar- \\ 249404 (Uttarakhand), India \\ *Present address: Department of Environmental Science, Integral University, Lucknow-226026 \\ (U.P.), India \\ Sanjive Shukla \\ P.G. Department of Zoology, B.S.N.V.P.G. College, Lucknow-226001, (U.P.), India \\ A. K. Chopra \\ Department of Zoology and Environmental Science, Gurukula Kangri University Haridwar- \\ 249404 (Uttarakhand), India \\ Sandeep Shukla \\ P.G. Department of Zoology, B.S.N.V.P.G. College, Lucknow-226001, (U.P.), India \\ Harnam Singh Lodhi \\ Department of Zoology, K.S. Saket P.G. College, Ayodhya - 224123 (U.P.), India \\ ${ }^{*}$ Corresponding author. E. mail: anand.mishra.am@gmail.com
}

\section{Article Info}

https://doi.org/10.31018/ jans.v12i3.2351

Received: August 2, 2020

Revised: September 8, 2020

Accepted: September 11, 2020

\section{How to Cite}

Mishra, A. et al. (2020). A report on freshwater tailless flea, Simocephalus vetulus from Haridwar, located in foothills of Shivalik Himalaya in Uttarakhand, India. Journal of Applied and Natural Science, 12(3): 438 - 441. https://doi.org/10.31018/jans.v12i3.2351

\begin{abstract}
The Cladocerans, commonly known as "Water fleas" form a primitive freshwater group of micro crustacean zooplankton of the freshwater ecosystem. They play an important role in the aquatic food chain and also contribute significantly to zooplankton dynamics and secondary productivity in freshwater ecosystems. The animals used in the present study were identified as Simocephalus vetulus with the help of identification keys described by various authors in the previous studies from other parts of India. In the present study, the occurrence of "freshwater tailless flea", S. vetulus (Crustacea- cladocera) is reported for the first time from freshwater bodies in Haridwar, located in foothills of Shivalik Himalayan region in Uttarakhand. The presence of S. vetulus "tailless water flea" will be helpful as a lab model for the health status of aquatic bodies as well as environmental monitoring.
\end{abstract}

Keywords: Biodiversity, Crustacea, Simocephalus vetulus, Tailless water flea

\section{INTRODUCTION}

Freshwater flea belongs to order cladocera of crustaceans they are found in freshwater aquatic bodies along with the submerged vegetation (Rumes et al., 2011). The common members belong to the family daphniidae, which are generally non-pelagic. Most widely studied genera of family daphniidae, Daphnia and Simocephalus which constitute of major place in the aquatic food chain. Genus Simocephalus commonly called as "tailless water flea" and are dominant species are a littoral community (Green, 2009; Mishra et al., 2016a; and 2016b; Thakur and Kocher, 2017; Mishra et al., 2018). Cladoceran species are widely used as test model toxicological, ecological and physi- ological studies (Freitas and Rocha, 2010; Smirnov, 2014; Sadeq and Beckerman, 2019). These species are also linked with commercial fisheries as many fishes and fry feed on zooplankton. They mature approximately in a week and can have thousands of offspring. During unfavourable weather conditions, they can produce resting eggs which can withstand time, heat, cold, and drought (Smirnov, 2014 and Mishra et al., 2016a and 2018). Therefore, proper identification and studies on $S$. vetulus are necessary considering the above facts. The present study was aimed to identify the water fleas present in the reservoirs of Haridwar, located in Shivalik foothills of Himalayan region in Uttarakhand. 


\section{MATERIALS AND METHODS}

Freshwater "tailless fleas" were collected from freshwater bodies in and around Haridwar mainly from "Bujaya Talab" located at village Jamaalpur Kala, "Madi Wala Talab" located at village Bahadarpur Jat and "Gram Devta Talab" located at Haridwar (latitude and longitude are $29.58^{\circ}$ north and $78.13^{\circ}$ east respectively) in Shivalik foothills of the Himalayan region. The collected fleas were brought to the laboratory. Identification was made using different morphological parameters like the size of carapace, rostrum, ocellus and shape of vertex, post abdominal claw and number of spines, as per Michael and Sharma (1988) and Battish (1992). Animals were maintained, and culture was propagated according to (Davis and Ford, 1992). Initially, the isolated $S$. vetulus were inoculated into the culture media. The animals were fed once in 24 hours (or as per experimental need) with a mixture of dried prawn powder in liquid form. Water was changed after feeding to avoid putrefaction leading to change in water qualities. They were maintained under constant vigil, and the lethargic and dead ones were removed quickly so as to avoid post-mortal changes resulting in contamination.

For microscopic studies, fleas were anaesthetized and fixed in Neutral Buffered Formalin (NBF pH 7.0 for $24 \mathrm{hr}$ ) as well as $80 \%$ ethyl alcohol, washed, dehydrated through series of ethanol, cleared in xylene and mounted in Canada balsam. Fleas were studied and photographed with Olympus trinocular research microscope. Camera Lucida diagram was drawn, and different parts of the fleas were measured using stage and ocular micrometres. The fleas were studied in living as well as preserved condition with the help of Olympus trinocular research microscope.

\section{RESULTS AND DISCUSSION}

The freshwater "tailless flea", are generally found in freshwater ponds located at Haridwar in Shivalik foothills of the Himalayan region of Uttarakhand and they were identified as Simocephalus vetulus (CrustaceaCladocera, Family- Daphniidae). Lateral-view images (Figs. 1 and 2) of S. vetulus were taken using a digital camera under a stereomicroscope for the morphometric study. Morphometric characters were extracted from photographic images. S. vetulus was translucent in colour and varied from blue-yellowish to olive-brown, sometimes with a greenish tinge. They were large, 1.7 $\mathrm{mm}$ to $2.0 \mathrm{~mm}$ in length, round or oval shape animals covered in a bivalve rounded carapace $(1.66 \mathrm{~mm})$. The head is small $(0.2 \mathrm{~mm})$, prominent; rounded in front which contains a single compound eye $(0.08 \mathrm{~mm})$ moderately large is not covered by this carapace but instead, it is surrounded by a hood. Attached to the head is a very small rostrum, ocellus elongated and the first antennules $(0.8 \mathrm{~mm})$, which contain olfactory setae. $S$. vetulus uses its second antennae as swimming appendages, and the five thoracic legs are used for filtering food and respiration. The dorsal side of the thorax, an extension of the carapace is called the brood pouch where the eggs are held. Post-abdomen very broad, deeply emarginated; Post-abdomen claw $(0.47 \mathrm{~mm})$ with 8 to 10 anal teeth on each side, anal teeth are gradually decreasing in size proximally (Figs. 1 and 2).

S. vetulus were observed to be non-pelagic, found in the littoral zone and in submerged aquatic vegetation in the freshwater aquatic body of the reservoir. They were filter feeders and fed algae, protozoan, organic detritus of the good size. In the laboratory, they readily consumed yeast and dried prawn powder. They swam freely and attached themselves easily to any rough surface during rest. Sometimes they attached themselves to a horizontal surface by anchoring curved setae on large rough surfaces.

The specimens of $S$. vetulus observed in the present study were identified as according to the characteristic features described above in the result segment. The important features considered were the shape of vertex, presence and absence of spinules on the vertex and the size of ocellus. The rounded vertex without

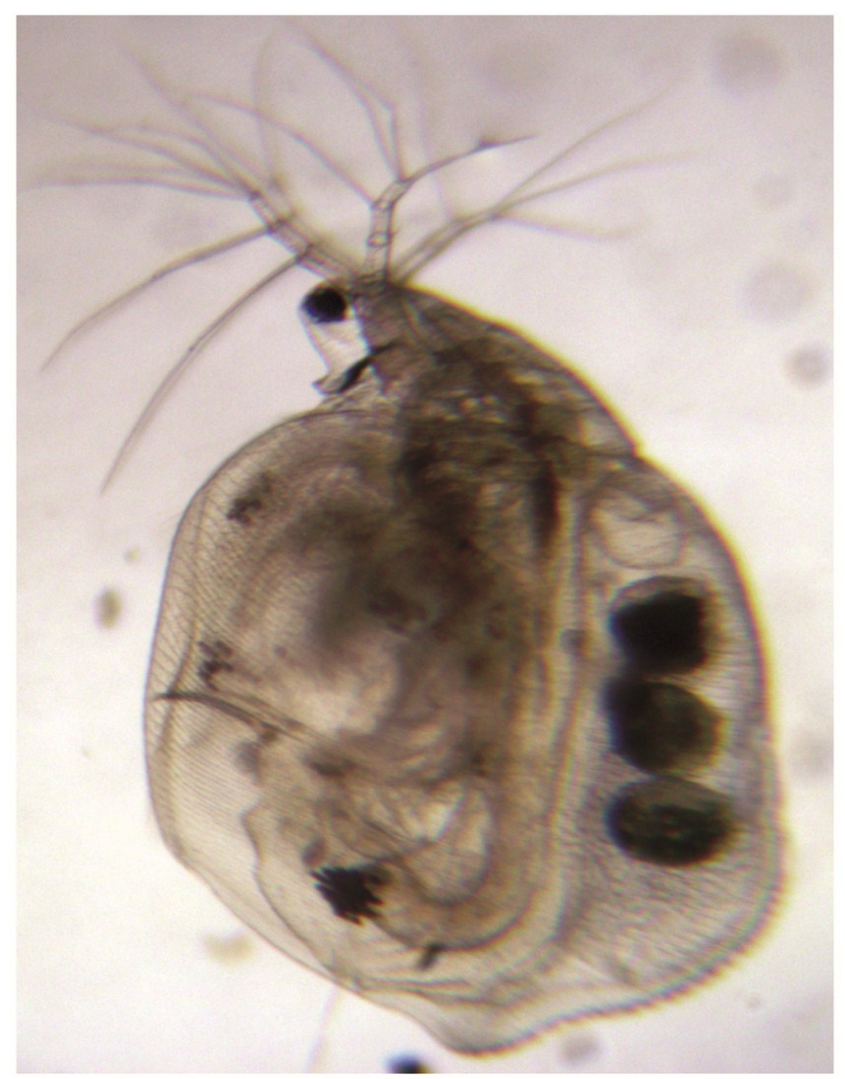

Fig. 1. Photomicrograph of Freshwater "tailless flea" Simocephalus vetulus (Crustacea: cladocera) (X40 Approx). 


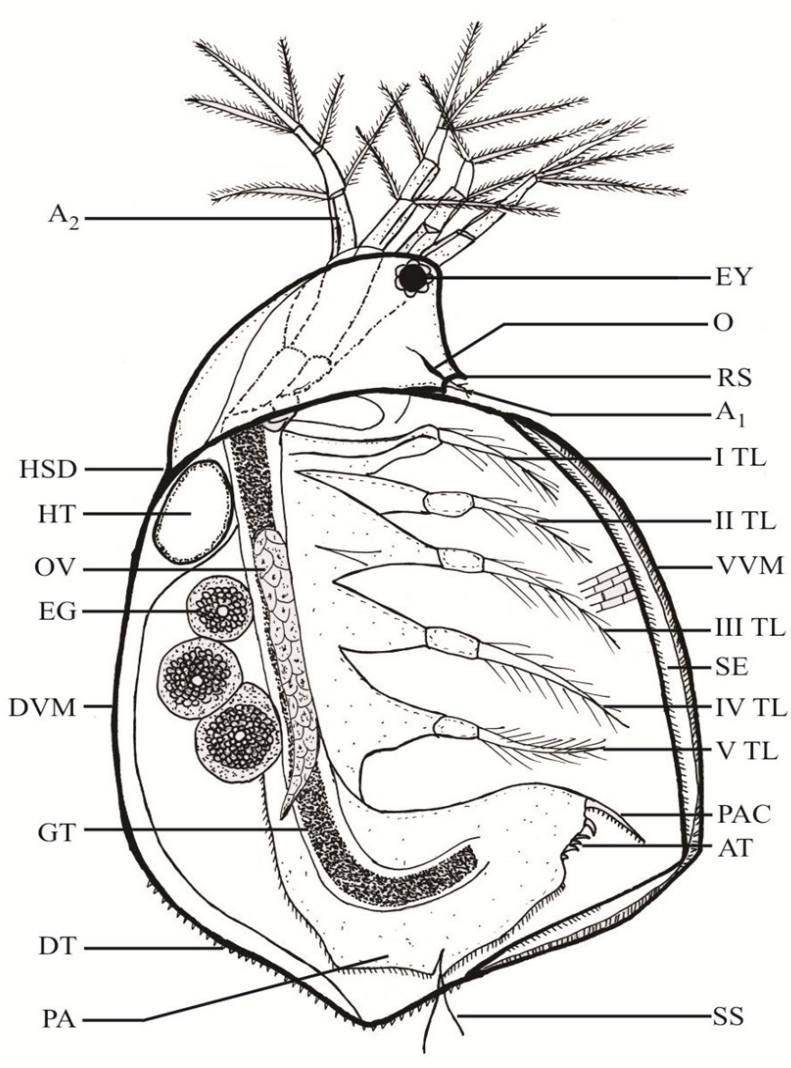

Fig. 2. Diagrammatic structure of Freshwater "tailless flea" Simocephalus vetulus (Female). Abbreviations: $A_{1}=$ Antennule, $A_{2}=$ Antenna, $A T=$ Anal teeth, $D T=$ Denticle, $D V M=$ dorsal valve margin, $E G=E g g s, E Y=E y e, G T=G u t$, $H T=$ Heart, $H S D=H e a d$ shield depression, $O=O c e l l u s$, OV=Ovary, $P A=$ Post abdomen, $P A C=$ Post abdominal claw, RS=Rostrum, SS=Sensory setae, SE=Setae, $V V M=V e n t r a l$ valve margin, I to $V^{\text {th }} T L=$ Thoracic legs.

spinules and presence of elongated ocellus clearly confirmed their identification as $S$. vetulus as described by Biswas, (1971); Nayar, (1971); Nasar, (1977); Sharma, (1978); Sharma and Sharma, (2001); Venkataraman, (2003); Chandrasekhar and Chatterjee, (2003) and Sharma et al., (2012).

The same species has also been reported from other different states of India, Punjab, Kashmir and Mysore (Brehm, 1936); Rajasthan (Biswas, 1971; Nayar, 1971; Sharma et al., 2012); Bihar (Nasar, 1977; Sharma and Sharma, 2001; Venkataraman, 2003); Kashmir (Yousuf and Qadri, 1977); West Bengal (Sharma, 1978 and Venkataraman, 2003) and Jharkhand (Chandrasekhar and Chatterjee, 2003). In the Northern Himalayan region, especially from Uttarpradesh (now Uttarakhand), this species has been reported from Kumaon, West Himalaya (Brehm, 1950). But from Haridwar located in Garhwal region of Uttarakhand, it is being reported for the first time.

S. vetulus are important aquatic organisms because they transfer energy from primary producers to consumers of higher trophic level, such as fish. At the same time, they are commonly used in measuring pollution level, drinking water quality and in the testing of human body fluids, due to their macroscopic size, easy culture methods, translucent body colours, short life span and parthenogenetic mode of reproduction. They are very sensitive to heavy metal toxicity.

\section{Conclusion}

On the basis of morphological characters like the size of carapace, rostrum, ocellus and shape of vertex, post abdominal claw and number of spines of tailless water fleas collected from the freshwater bodies of Haridwar, located in Shivalik foothills of Himalaya region of Uttarakhand, were identified as $S$. vetulus. They are the important member of the aquatic food chain, can serve a good bioindicator; hence present study will be helpful in monitoring the productivity and health status of the water bodies present in and around of Shivalik foothills of the Himalayan region.

\section{ACKNOWLEDGEMENTS}

Authors are thankful to Head, Department of Zoology and Environmental Science, Gurukula Kangri Vishwavidyalaya, Haridwar (Uttarakhand) and Head, Department of Zoology, B.S.N.V.P.G. College, Lucknow (Uttar Pradesh), India for providing necessary facilities, and also thankful to Prof. U. D. Sharma, Retd. Professor, Department of Zoology, University of Lucknow, Lucknow- 226007 (Uttar Pradesh) for suggestions.

\section{REFERENCES}

1. Battish, S. K. (1992). Freshwater Zooplankton of India. Oxford \& IBH Publishing Co. Pvt. Ltd., Pp.130-172.

2. Biswas, S. (1971). Fauna of Rajasthan, India. Part II. (Crustacea: Cladocera). Rec. Zool. urv. India, 63: 95-141.

3. Brehm, (1936). Yale North India Expedition. Report on Cladocera. Article XVI. Meln. Conn. A cad, Arts. Sci., 10: 283-297.

4. Brehm, V. (1950). Contribution to the freshwater fauna of India, Part I \& II. Records of the Indian Museum, 48(1-3): 928.

5. Chandrasekhar, S. V. A. and Chatterjee, T. (2003). On a collection of Cladocera from Dimna and Jublee park lakes, Jamshedpur, Jharkhand. Zoos' Print Jour., 18(4): 1089-1090.

6. Davis, L., Ford, P. (1992). Toxicity reduction evaluation and control. Technomic Publishing Company Inc.

7. Freitas, E. and Rocha, O. (2010). Acute toxicity tests with the tropical Cladoceran Pseudosida ramosa: The importance of using native species as testoOrganisms. Archi. Environ. Contamin. Toxicol., 60(2):241-9. DOI: $10.1007 / \mathrm{s} 00244-010-9541-2$.

8. Green, J. (2009). Variation in carotenoid pigmentation of Simocephalus vetulus (Crustacea: Cladocera). J. of Zool., 149(2):174-187. DOI: 10.1111/j.1469-7998.1966.tb03 892.x. 
9. Michael, R. G. and Sharma, B. K. (1988). Fauna of India, Indian Cladocera (Crustacea: Branchiopoda: Cladocera) Edited by the Director, Zoological Survey of India, Calcutta.

10.Mishra, A., Shukla, S. and Chopra, A. K. (2016a). Acute toxicity of copper sulphate and potassium chromate to "tailless freshwater flea", Simocephalus vetulus (Crustacea-Cladocera). Inter. J. Adv. Res., 4(6): 316-321. DOI:10.21474/IJAR01/648.

11.Mishra, A., Shukla, S. and Chopra, A. K. (2016b). Physiological responses of heart of tailless fresh water flea Simocephalus vetulus (Crustacea-cladocera) under copper sulphate stress). CIBTech J. Zool., 5(3): 52-59.

12.Mishra, A., Shukla, S. and Chopra, A. K. (2018). Effect of heavy metal, copper sulphate and potassium chromate on behaviour of "Tailless water flea" Simocephalus vetulus (Crustacea - Cladocera). Journal of Applied and Natural Science., 10 (1): 507-517. DOI:10.31018/jans.v10i1.1659.

13.Nasar, S. A. K. (1977). The zooplankton fauna of Bhagalpur (Bihar) II. Cladocera. Carcinological Society of Japan. Researches on Crustacea, No.8:32-36.

14.Nayar, C.K.G. (1971). Cladocera of Rajasthan. Hydrobiologia., 37 : 509-519.

15.Rumes, B., Eggermont, H. and Verschuren, D. (2011). Distribution and faunal richness of Cladocera in western Uganda crater lakes. Hydrobiologia, 676(1):39-56. DOI: 10.1007/s10750-011-0829-7.
16.Sadeq, S. A. and Beckerman, A. P. (2019). The chronic effects of copper and cadmium on Life History Traits Across Cladocera Species: A Meta-analysis. Arch. Environ. Contam. Toxicol., 76(1): 1-16. DOI: 10.1007/s00244018-0555-5.

17.Sharma, B. K. (1978). A note on Freshwater cladocerans from West Bengal. Bangladesh J. Zool., 6: 149-151.

18.Sharma, B. K. and Sharma, S. (2001). Contributions to the cladoceran fauna (Crustacea: Branchiopoda:Cladocera) of Bihar. Rec. Zool. Surv. India: 99 (Part 1-4): 31-43.

19.Sharma, V., Verma, B. K., Sharma, R., Sharma, M. S. and Gaur, K. S. (2012). A report on the freshwater Cladocera (Crustacea: Branchiopoda) of south Rajasthan (India). International Jour. of Environ. Sci., 3(1): 275-296. DOI:10.6088/ijes.2012030131027.

20.Smirnov, N. N. (2014). Physiology of the cladocera. Academic Press is an imprint of Elsevier., pp-196. DOI: http:// dx.doi.org/10.1016/B978-0-12-396953-8.00002-1.

21.Thakur, A. and Kocher, D. K. (2017). Diversity and density of cladoceran population in different types of water bodies of Ludhiana, Punjab (India). Journal of Entomology and Zoology Studies, 5(3): 1568-1572.

22. Venkataraman, K. (2003). Crustacean Zooplankton of Damodar River. Rec. Zool. Surv. India: 101 (Part 1-2): 209-229.

23. Yousuf, A. R. and Qadri, M. Y. (1977). Cladocera of Malpur Sar, Kashmir. J. Sci. Univ. Kash., 3: 87-92. 